\title{
Fatores que afetam a freqüência e o atraso escolar, nos meios urbano e rural, de São Paulo e Pernambuco
}

Rosangela Maria Pontili* Ana Lúcia Kassouf**

Resumo: Diversos trabalhos da literatura econômica têm mostrado a influência da educação na melhoria de renda das pessoas e no desenvolvimento econômico de um país. Entretanto, para melhorar o nível médio de escolaridade de um país é importante elevar a freqüência escolar e garantir à criança o avanço nos estudos. Preocupado com essa questão o Governo Federal brasileiro realizou diversas reformas no sistema educacional, especialmente a partir da década de 1990. Em vista disso, o presente trabalho fez uma análise da influência que variáveis associadas a características pessoais e familiares de uma criança, bem como variáveis de infra-estrutura escolar exercem sobre a freqüência e o atraso escolar no ensino fundamental, comparando-se as áreas urbana e rural, de Pernambuco e São Paulo. Os resultados mostraram que políticas voltadas para melhorar a escolaridade do chefe de família e/ou a renda familiar per capita podem aumentar a freqüência e reduzir o atraso escolar. Entretanto, iniciativas voltadas para melhorar a infra-estrutura escolar deverão levar em conta a realidade econômica do estado ou região e o objetivo final a ser alcançado. Além disso, os indicadores educacionais estudados são mais precários na área rural e merecem a elaboração de políticas públicas especialmente voltadas para essa realidade.

\footnotetext{
* Mestre em economia aplicada pela ESALQ, Universidade de São Paulo e Professora Assistente da Faculdade Estadual de Ciências e Letras de Campo Mourão (FECILCAM). rpontili@yahoo.com.br

**Professora Titular do Departamento de Economia, Adm. e Soc. da ESALQ, Universidade de São Paulo e pesquisadora do Cepea. alkassou@esalq.usp.br.
} 
Palavras-chave: educação, meios urbano e rural, políticas públicas.

\section{Classificação JEL: I21}

Abstract: Many studies in the economic field have showed the importance of education to increase the wellbeing of the society. Trying to improve the educational indicators, in the 90's, many changes were implemented in the Brazilian public school system. The objective of the present study is to evaluate school infrastructure and family characteristics affecting children's decision to study or to drop out from school (frequency and school delay in primary and secondary levels), comparing the urban and rural areas of Pernambuco and São Paulo. The results showed that policies that would increase parents' schooling and/or family income would increase frequency and decrease delay in school. However, policies that would improve the schools' infrastructure and consequently the quality of the schools would have to take the socio-economic aspects of the region into consideration as well as the type of objective to be reached. Moreover, the investments should be focused on rural areas where educational indicators are far behind.

Key words: education, rural and urban areas, public policies

\section{JEL Classification: 121}

\section{Introdução}

A preocupação com a influência da educação no nível de desenvolvimento econômico de um país tem se tornado cada vez mais freqüente na literatura econômica nacional e internacional. No trabalho de Behrman \& Wolfe (1984) comprovou-se que investimentos em educação provocam um impacto socioeconômico positivo na geração de renda de países em desenvolvimento. Outros trabalhos preocuparam-se em verificar a influência de programas governamentais na educação e na renda das pessoas [Card \& Krueger (1992); Duflo (2001)], bem como a evolução dos retornos obtidos com investimentos em educação (Blom et al., 2002) e a influência das diferenças de escolaridade nos 
rendimentos do trabalho (Pereira, 2001). Trabalhos feitos para o Brasil mostraram que o acréscimo de um ano na escolaridade eleva a renda dos indivíduos em até 16\% [Kassouf, (1997); Kassouf, (2001); Ueda \& Hoffmann, (2002); Barros \& Ramos, (1992)].

Sabe-se, no entanto, que o primeiro passo para elevar o nível médio de escolaridade de um país é elevar a freqüência escolar e manter a criança na escola, garantindo-lhe o avanço de seus níveis educacionais. Em vista disso, têm-se pesquisas que avaliaram a importância das características familiares e comunitárias, bem como de outros fatores socioeconômicos, nos níveis de escolaridade alcançados por uma pessoa [Holmes (1999); Tansel (2000); Barros et al. (2001); Vasconcellos (2003)].

Tendo em vista a importância da escolaridade na vida da pessoa e no nível de renda nacional, o Governo Federal brasileiro realizou diversas reformas, especialmente a partir da década de 1990, com o objetivo de melhorar os índices educacionais do país. Segundo Barros \& Mendonça (1998), a promulgação da Constituição Federal de 1988 representou um avanço para a sociedade, ao permitir maior autonomia e descentralização do ensino brasileiro. Em 1996 foi aprovada a Lei de Diretrizes e Bases da Educação Nacional (LDB) e criado o Fundo de Manutenção e Desenvolvimento do Ensino Fundamental e de Valorização do Magistério (FUNDEF) (Brasil, 2003). Tem-se, ainda, a preocupação com a melhoria na infra-estrutura das escolas que oferecem o ensino fundamental. Entre 1999 e 2003 o número de escolas com biblioteca aumentou de 23,5\% do total de escolas no Brasil, para 28,9\% e o número de escolas com laboratórios de informática saiu de uma proporção de 7,7\% do total de estabelecimentos de ensino, para 13,6\% (Brasil, 2004). Outra iniciativa diz respeito à transferência de renda direta às famílias, através de programas como o Bolsa-Escola, atualmente incorporado ao Bolsa-Família. Destaca-se, também, a preocupação em melhorar os níveis educacionais de pessoas analfabetas ou com idade superior à recomendada para cursar o ensino fundamental ${ }^{1}$, através de programas de "Educação de Jovens e Adultos".

\footnotetext{
${ }^{1}$ A LDB afirma que é dever dos pais ou responsáveis efetuar a matrícula dos menores, a partir dos sete anos de idade, no ensino fundamental (LDB, art. $6^{\circ}$ ). Como o ensino fundamental tem duração de 8 anos, a faixa etária adequada para cursar esse nível de ensino ocorre entre 7 e 14 anos.
} 
As iniciativas acima mencionadas retratam a preocupação do governo com a universalização do ensino fundamental e com a melhoria dos indicadores de atraso escolar do Brasil. Porém, tanto a freqüência, quanto o atraso escolar variam de acordo com a realidade socioeconômica dos estados e regiões. Utilizando-se os dados da Pesquisa Nacional por Amostra de Domicílios (PNAD) de 2001, percebe-se que em São Paulo o percentual de crianças entre 7 e 14 anos que estavam estudando, na zona rural, era 97,39\% . Enquanto isso, na zona urbana 98,02\% dessas crianças estavam na escola. Na zona rural de Pernambuco a porcentagem de crianças, dessa faixa etária, que estavam estudando era de $93,66 \%$, enquanto na zona urbana esse percentual era de $94,31 \%$. Além disso, em Pernambuco, a porcentagem de alunos, com idade inferior a 25 anos, que estavam atrasados na escola, era de 56\% na zona rural e $41 \%$ na zona urbana. Em São Paulo, tais percentuais eram de $24 \%$ dos residentes na área rural e $15 \%$ dos moradores na área urbana.

As informações acima levam a questionar até que ponto as iniciativas que melhoram a infra-estrutura escolar, estão influenciando as alterações no número total de matrículas e no resultado escolar das crianças do ensino fundamental nos dois estados. Além disso, outros fatores econômicos e sociais podem estar influenciando a decisão de estudar e o atraso escolar do aluno. Dentre estes, podem ser citados a escolaridade do chefe de família e a renda familiar per capita.

Em vista disso, o objetivo desse trabalho foi o de verificar como variáveis associadas às características familiares e às características da infra-estrutura escolar afetam a probabilidade de freqüência e de atraso escolar, de pessoas residentes nos meios urbano e rural, de Pernambuco e São Paulo.

\section{Metodologia e dados}

Com o objetivo de modelar uma equação para a freqüência e o atraso escolar, de São Paulo e Pernambuco, fez-se uso do modelo próbite, no qual a variável dependente é qualitativa (Greene, 2003). Serão, portanto, apresentados, os efeitos marginais do referido modelo, representado por:

$$
\mathbf{y}, \mathbf{z}=F^{l}\left(\mathbf{x}_{c}, \mathbf{x}_{f}, \mathbf{x}_{e}\right) \quad l=\mathbf{y}, \mathbf{z}
$$


onde:

y é a freqüência, atribuindo-se valor $\mathbf{0}$ a não freqüência e $\mathbf{1}$ a freqüência à escola;

$\mathbf{z}$ é o atraso, que assume valor $\mathbf{1}$ para as crianças com defasagem e valor $\mathbf{0}$ para aquelas sem defasagem escolar.

Os vetores de variáveis explicativas, utilizados nos dois modelos, foram os mesmos, sendo $\mathbf{x}_{c}$, o vetor das características individuais da criança, incluindo-se aí, variáveis de controle para as diferenças étnicas e regionais. $\mathrm{O}$ vetor $\mathbf{x}_{\mathrm{f}}$ representa as características familiares de cada criança e o vetor $\mathbf{x}_{\mathrm{e}}$ refere-se às características da infra-estrutura escolar.

Para fazer a análise proposta foram utilizados: o Censo Demográfico do ano 2000, que foi desagregado até o nível de municípios, do qual foram selecionadas as variáveis das características pessoais e familiares da criança, bem como a renda e a escolaridade média dos professores; O censo escolar também de 2000, do qual se extraiu as variáveis referentes à proporção de escolas com bibliotecas e laboratórios de informática, além do número de alunos por turma em cada município; as informações referentes aos repasses do Programa Dinheiro Direto para a Escola (PDDE), do Programa Nacional de Alimentação Escolar (PNAE), além do FUNDEF, tendo-se calculado a média de repasses por aluno, no ano 2000, para cada município dos dois estados. Todos os dados referentes às características da infra-estrutura escolar foram repetidos para cada criança dentro de cada município, para a realização das análises.

As variáveis escolhidas foram divididas em dois bancos de dados diferentes. O primeiro foi utilizado para as análises da freqüência escolar e nele foram selecionadas todas as crianças, com idade entre 7 e 14 anos, tanto para São Paulo, quanto para Pernambuco, excluindo-se aquelas que freqüentavam creche ou pré-escola. Por fim, excluíram-se os estudantes de escolas particulares.

Quanto ao banco de dados da variável atraso escolar foram selecionadas todas as pessoas que estudavam no ensino fundamental, com até 24 anos, chegando-se a 98\% do total de estudantes, em São Paulo e $95 \%$ em Pernambuco. Dos estudantes com idade inferior a 24 anos foram excluídos aqueles que declararam ser a pessoa de referência da família e os estudantes de escolas particulares. A variável atraso escolar 
foi calculada levando em consideração os critérios adotados pelo MEC, para se encontrar a taxa de distorção idade-série.

O programa utilizado para fazer a seleção dos bancos de dados foi o SAS for Windows V8 e o programa usado para rodar as regressões foi o Stata 8.0. Além disso, os resultados foram ponderados pelo fator de expansão da amostra, do Censo Demográfico. As médias e desvios-padrão das variáveis selecionadas estão nos anexos deste trabalho.

\section{Resultados e Discussão}

Seguem, abaixo, as análises dos efeitos marginais das regressões próbite para a freqüência e o atraso escolar. Em todas as regressões foram incluídas as mesorregiões dos dois estados, como variáveis de controle das diferenças culturais e regionais. Dentre as variáveis que são proxy da infra-estrutura escolar, a melhoria da escolaridade e da renda média do professor, assim como a redução do número de alunos por turma representam investimentos na qualidade do ensino. Por outro lado, aumentar a proporção de escolas com biblioteca, ou com laboratórios de informática, significa melhorar a capacidade física da escola. Finalmente, os repasses aos programas PNAE, PDDE e FUNDEF representam investimentos diretos do Governo Federal no ensino fundamental dos dois estados. Dentre essas variáveis, foram excluídas, nas regressões, as que foram não significativas e apresentaram problemas de multicolinearidade com alguma outra variável do modelo.

A Tabela 1 mostra que, para o caso da freqüência escolar, os coeficientes das variáveis associadas às características individuais da criança foram todas significativas, tanto na área urbana, quanto na área rural, dos dois estados. Em todas as regressões a freqüência à escola aumenta com a idade, até certo limite, passando a reduzir-se com a idade a partir de então. Na maioria dos casos, as meninas estão mais propensas a freqüentar a escola que os meninos, exceto na área rural de São Paulo. Em todas as regressões os negros têm menor probabilidade de freqüentar a escola que os brancos, ocorrendo o mesmo com os pardos da área rural de Pernambuco e urbana de São Paulo. Tais resultados são similares aos encontrados por Vasconcellos (2003), que fez uma análise dos fatores determinantes da freqüência e atraso escolar, para o Brasil. Confirma-se, portanto, que as diferenças inter-raciais existentes no país também podem ocorrer 
nos estados. Os coeficientes associados aos pardos da área rural de São Paulo e urbana de Pernambuco, bem como aqueles referentes às pessoas de cor amarela, não foram significativos ao nível de $10 \%$.

A maioria das variáveis que representam as características da família foi significativa e apresentou o sinal esperado. Destaca-se, assim, que melhorar a renda familiar per capita, assim como a escolaridade da pessoa responsável pela família, das crianças residentes nas áreas urbana e rural, pode levar a um aumento da freqüência escolar, nos dois estados. Para Barros et al. (2001) a magnitude dos coeficientes associados à escolaridade das pessoas responsáveis pela família pode ser preocupante, quando se trata de famílias pobres com pais menos escolarizados. Nesse caso, os filhos também poderiam adquirir uma educação menor e, conseqüentemente, os netos, provocando um mecanismo de transmissão intergeracional de pobreza. Um efeito positivo e significativo para a variável renda também foi encontrado no trabalho de Vasconcellos (2003), no qual famílias pertencentes a quartis mais elevados de renda têm maior probabilidade de matricular seus filhos na escola.

Com relação às variáveis da infra-estrutura escolar, os resultados mostram que na área urbana de São Paulo um aumento na escolaridade do professor, assim como na proporção de escolas com biblioteca e laboratórios de informática, afeta de maneira positiva a freqüência de alunos na escola. No entanto, as variáveis da média salarial do professor e dos repasses do PDDE apresentaram um sinal diferente do esperado, ocorrendo o mesmo nas regressões para a área rural. Acredita-se que essas variáveis estejam captando efeitos não controlados na amostra. Professores com melhor remuneração, em geral, são mais velhos, pois sua melhoria de renda está diretamente ligada ao tempo de serviço no magistério. As dificuldades enfrentadas ao longo da carreira podem condicionar o desinteresse do professor em motivar as crianças para o ingresso e permanência na escola. Arends-Kuenning et al. (2004), ao contrário, fazendo uma análise para o Brasil, com dados da PNAD, encontraram um sinal positivo para esta variável, confirmando a hipótese de que melhorias no salário do professor podem aumentar a matrícula escolar. Nesse trabalho, foi incluída a variável tempo de serviço, que não está disponível no censo demográfico. Finalmente, na área rural, de São Paulo, a freqüência escolar é afetada positivamente por melhorias na escolaridade do professor e nos repasses do FUNDEF. 
No caso de Pernambucano, as variáveis da infra-estrutura escolar apresentaram resultados bem distintos. Melhorias no salário do professor afetam positivamente a freqüência escolar de crianças da área urbana, enquanto na área rural ocorre influência positiva dos aumentos na escolaridade do professor. Este segundo resultado é similar ao encontrado por Birdsall (1985). Com relação à capacidade física, é mais interessante aumentar a proporção de escolas com biblioteca na área rural e a proporção de escolas com laboratório de informática na área urbana. Além disso, tanto as verbas destinadas ao PNAE, quanto as transferências do FUNDEF têm se mostrado importante para aumentar a freqüência escolar de Pernambuco. Cabe lembrar, que é comum no Brasil as afirmativas nas quais crianças pertencentes a famílias pobres freqüentam a escola em busca da "merenda escolar", visto que estão submetidas à ausência de uma refeição diária de qualidade em seus próprios lares. Esta pode ser uma situação comum nas regiões mais pobres do país.

Na Tabela 2 pode ser visto que o atraso escolar do estudante paulista diminui com a idade até, aproximadamente, 13 anos na zona urbana e 7 anos na zona rural, passando a aumentar com a idade após esse limite. No caso de Pernambuco, existe uma forte tendência de aumentos na probabilidade de atraso escolar, conforme se aumenta a idade do estudante. Em todas as regressões, a probabilidade de atraso escolar para os meninos é maior que para as meninas. Tal resultado é similar ao encontrado por Ferrão et al. (2002) que, utilizando dados do Sistema de avaliação do ensino básico (Saeb), fez uma análise para o Brasil e mostrou que meninos têm maiores problemas de defasagem escolar que meninas.

Com relação à cor ou raça, tanto os negros, quanto os pardos, têm maiores chances de ficarem atrasados na escola que os brancos. Os amarelos atrasam-se menos, na escola, que os brancos da área urbana de São Paulo, ocorrendo o contrário na área rural de Pernambuco. As diferenças raciais do Brasil foram percebidas por Albernas et al. (2002), em uma pesquisa que foi realizada utilizando dados do exame Saeb de 1999. Ao observar o desempenho desses alunos no exame Saeb, percebeu-se que os pardos ou mulatos tinham um desempenho inferior ao dos alunos brancos em 2,5 pontos. Diferença, essa, que aumentava quando se tratava de alunos pretos. Para os autores a constatação das desigualdades de oportunidades é um resultado preocupante e que deve ser levado em conta pelas autoridades governamentais. 
Tabela 1 - Efeitos marginais das regressões próbite para a freqüência escolar no ensino fundamental, de escolas públicas, de São Paulo e Pernambuco - áreas urbana e rural.

\begin{tabular}{|c|c|c|c|c|}
\hline \multirow[b]{2}{*}{ Variáveis } & \multicolumn{2}{|c|}{ São Paulo } & \multicolumn{2}{|c|}{ Pernambuco } \\
\hline & Urbano & Rural & Urbano & Rural \\
\hline Idade & $0,0511^{*}$ & $0,104 *$ & $0,106^{*}$ & $0,164^{*}$ \\
\hline Idade ao quadrado & $-0,00252^{*}$ & $-0,00531^{*}$ & $-0,00513^{*}$ & $-0,00774 *$ \\
\hline Sexo $($ menino $=1)$ & $-0,00267^{*}$ & $0,00888^{*}$ & $-0,0185^{*}$ & $-0,0223^{*}$ \\
\hline \multicolumn{5}{|l|}{ Cor ou raça (Branca foi omitida) } \\
\hline Preta & $-0,00645^{*}$ & $-0,0333^{*}$ & $-0,0176^{*}$ & $-0,0174^{* *}$ \\
\hline Amarela & $-0,00674$ & $-0,00937$ & $-0,00645$ & $-0,0196$ \\
\hline Parda & $-0,00203^{*}$ & 0,00191 & $-0,00247$ & $-0,00731^{* *}$ \\
\hline \multicolumn{5}{|c|}{ Mesorregiões (Região metropolitana foi omitida nos dois estados) } \\
\hline São José do Rio Preto & $0,00479^{*}$ & $0,0310^{* *}$ & - & - \\
\hline Ribeirão Preto & 0,000255 & 0,0146 & - & - \\
\hline Araçatuba & $0,00695^{*}$ & $0,0363^{* *}$ & - & - \\
\hline Bauru & $-0,00229$ & $-0,0511^{* *}$ & - & - \\
\hline Araraquara & $0,00420^{* *}$ & 0,0223 & - & - \\
\hline Piracicaba & $0,00473^{*}$ & 0,0123 & - & - \\
\hline Campinas & $-0,00303^{*}$ & $-0,00477$ & - & - \\
\hline Presidente Prudente & $0,00873^{*}$ & 0,0385 & - & - \\
\hline Marília & $0,00596 * *$ & $0,0308^{* *}$ & - & - \\
\hline Assis & $0,00419^{* *}$ & 0,0149 & - & - \\
\hline Itapetininga & $-0,00968^{*}$ & $-0,0290^{*}$ & - & - \\
\hline Macro-região & $-0,00115$ & $-0,0166^{* *}$ & - & - \\
\hline Vale do Paraíba & $0,00479^{*}$ & 0,00505 & - & - \\
\hline Litoral Sul & $-0,00809^{*}$ & $-0,0175^{* *}$ & - & - \\
\hline Sertão Pernambucano & - & - & 0,00163 & 0,00286 \\
\hline São Francisco & - & - & $-0,0111^{* *}$ & 0,00705 \\
\hline Agreste Pernambucano & - & - & $-0,0271^{*}$ & 0,00804 \\
\hline Zona da Mata & - & - & $-0,0192^{*}$ & $-0,000203$ \\
\hline \multicolumn{5}{|l|}{ Características da família } \\
\hline Log. da renda familiar per capita & $0,00549^{*}$ & $0,0101^{*}$ & $0,010^{*}$ & $0,00748^{*}$ \\
\hline Idade do chefe da família & $0,000238^{*}$ & $0,000399 * *$ & $0,000317^{*}$ & $-0,0000188$ \\
\hline Escolaridade do chefe da família & $0,00254^{*}$ & $0,0060^{*}$ & $0,00796^{*}$ & $0,0153^{*}$ \\
\hline Sexo do chefe da família $($ homem $=1$ ) & $0,00496^{*}$ & 0,0060 & $0,0192 *$ & $0,0221 *$ \\
\hline \multicolumn{5}{|l|}{ Características da infra-estrutura escolar } \\
\hline Média de anos de estudo do professor & $0,00261^{*}$ & $0,00115^{* * *}$ & $-0,00787^{*}$ & $0,00209^{* * *}$ \\
\hline Log. da média salarial do professor & $-0,00632^{*}$ & $-0,00816^{*}$ & $0,0183^{* *}$ & $-0,020^{*}$ \\
\hline Proporção de escolas com biblioteca & $0,00476^{* *}$ & $-0,000115$ & 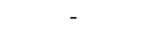 & $0,000558^{*}$ \\
\hline Proporção de escolas c/ lab. informática & $0,00461^{* *}$ & 0,01285 & $0,0680^{*}$ & - \\
\hline Média de alunos por turma & $-0,000135$ & 0,0000124 & 0,000086 & $-0,000558^{*}$ \\
\hline Repasses do PNAE (média) & 0,000187 & - & $0,00779 *$ & $0,0149^{*}$ \\
\hline Repasses do PDDE (média) & $-0,000155^{*}$ & $-0,00192^{*}$ & - & - \\
\hline Repasses do FUNDEF (média) & - & $0,000229^{* *}$ & $0,000636^{*}$ & $0,000814^{* *}$ \\
\hline Número de observações & 449.682 & 22.151 & 73.372 & 45.762 \\
\hline Teste Razão de Verossimilhança & $5.825,44^{*}$ & $738,27 *$ & $1.573,30^{*}$ & $989,11 *$ \\
\hline
\end{tabular}

Fonte: resultados da pesquisa

Nota: *denota significância ao nível de $1 \%$; **denota significância ao nível de 5\%; ***denota significância ao nível de $10 \%$. 
Com relação às características familiares, somente as variáveis que representam o sexo e a idade do chefe de família, das zonas rurais de São Paulo e Pernambuco, respectivamente, foram não significativas. Nos outros casos, aumentos na renda familiar per capita do estudante, bem como na idade e escolaridade do chefe de família, podem contribuir com reduções na probabilidade de atraso escolar. Ferrão et al. (2002), também encontraram uma correlação negativa entre a defasagem idade-série e o nível socioeconômico do aluno. Além disso, na análise de Leon \& Menezes-Filho (2002) o chefe de família era menos escolarizado entre as crianças reprovadas no ensino fundamental, quando comparadas àquelas que teriam sido aprovadas.

Percebe-se, ainda, que em famílias chefiadas por mulher, as chances de aumento no atraso escolar são maiores, do que em famílias chefiadas por homens. Em geral, é comum que em lares chefiados por mulheres ocorra a ausência da figura paterna, o que obriga as mães a sustentarem a casa, tendo menos tempo para seus filhos e filhas. Também pode ocorrer que essas mães coloquem os filhos (ou filhas) para trabalhar, reduzindo o tempo disponível para as crianças estudarem (tanto em casa, quanto na escola). Tal situação pode levar à defasagem escolar.

$\mathrm{Na}$ análise para a infra-estrutura escolar supunha-se que em turmas muito numerosas o aluno tivesse maior dificuldade para obter a atenção do professor, em relação a não compreensão da matéria, o que levaria a reprovações e aumentos no atraso escolar. No entanto, nas regressões para o Estado de São Paulo, a variável da média de alunos por turma apresentou um sinal contrário ao esperado. Apesar disso, Bertagna (2003) comenta que os profissionais entrevistados em sua pesquisa afirmaram que o trabalho individualizado junto ao aluno é prejudicado quando as classes são muito numerosas, impossibilitando a aprendizagem efetiva da criança.

Na área urbana de São Paulo, aumentos na escolaridade média do professor e na proporção de escolas com laboratório de informática são estratégias mais interessantes para se obter a redução do atraso escolar. Entretanto, na área rural, é mais interessante aumentar o número de escolas com biblioteca e os repasses do PNAE. A variável que representa a média salarial do professor apresentou um sinal diferente do esperado, nas zonas urbanas, tanto de São Paulo, quanto de Pernambuco. 
Tabela 2 - Efeitos marginais das regressões próbite para o atraso escolar no ensino fundamental, de escolas públicas, de São Paulo e Pernambuco áreas urbana e rural.

\begin{tabular}{|c|c|c|c|c|}
\hline \multirow{2}{*}{ Variáveis } & \multicolumn{2}{|c|}{ São Paulo } & \multicolumn{2}{|c|}{ Pernambuco } \\
\hline & Urbano & Rural & Urbano & Rural \\
\hline Idade & $-0,0859 *$ & $-0,0342^{*}$ & $0,179^{*}$ & $0,370^{*}$ \\
\hline Idade ao quadrado & $0,00639 *$ & $0,00511^{*}$ & $-0,00088^{*}$ & $-0,00884^{*}$ \\
\hline Sexo $($ menino $=1)$ & $0,0380^{*}$ & $0,0469 *$ & $0,155^{*}$ & $0,142 *$ \\
\hline \multicolumn{5}{|l|}{ Cor ou raça (Branca foi omitida) } \\
\hline Preta & $0,0466^{*}$ & $0,0699 *$ & $0,0911^{*}$ & $0,0913^{*}$ \\
\hline Amarela & $-0,0219 * *$ & $-0,0541$ & $-0,0501$ & $0,204^{*}$ \\
\hline Parda & $0,0292^{*}$ & $0,0355^{*}$ & $0,0418^{*}$ & $0,040^{*}$ \\
\hline \multicolumn{5}{|c|}{ Mesorregiões (Região metropolitana foi omitida) } \\
\hline São José do Rio Preto & $-0,0192 *$ & $-0,0732 *$ & - & - \\
\hline Ribeirão Preto & $-0,00634^{*}$ & 0,0115 & - & - \\
\hline Araçatuba & $-0,0231^{*}$ & $-0,0543 * * *$ & - & - \\
\hline Bauru & $-0,00640 * *$ & $-0,0219$ & - & - \\
\hline Araraquara & $-0,0239^{*}$ & $-0,0511 * *$ & - & - \\
\hline Piracicaba & $-0,00899 *$ & $-0,0322 * *$ & - & - \\
\hline Campinas & 0,00242 & 0,00499 & - & - \\
\hline Presidente Prudente & $-0,0317^{*}$ & $-0,0551^{*}$ & - & - \\
\hline Marília & $-0,0102 * *$ & $-0,0417^{* *}$ & - & - \\
\hline Assis & $-0,0117^{*}$ & $0,0561 * *$ & - & - \\
\hline Itapetininga & 0,00414 & $-0,0344^{*}$ & - & - \\
\hline Macro-região & $-0,0121^{*}$ & $-0,0216^{* *}$ & - & - \\
\hline Vale do Paraíba & $-0,00985^{*}$ & 0,0099 & - & - \\
\hline Litoral Sul & 0,00298 & $-0,0146$ & - & - \\
\hline Sertão Pernambucano & - & - & $0,0311^{*}$ & $-0,0112$ \\
\hline São Francisco & - & - & $-0,0147$ & $-0,010$ \\
\hline Agreste Pernambucano & - & - & 0,0389 & $0,0502^{*}$ \\
\hline Zona da Mata & - & - & $0,0149^{* *}$ & $0,0396 * *$ \\
\hline \multicolumn{5}{|l|}{ Características da família } \\
\hline Log. da renda familiar per capita & $-0,0163^{*}$ & $-0,0253^{*}$ & $-0,0414^{*}$ & $-0,0311^{*}$ \\
\hline Idade do chefe da família & $-0,000929 *$ & $-0,000589 * *$ & $-0,000506^{*}$ & $-0,0000602$ \\
\hline Escolaridade do chefe da família & $-0,0104^{*}$ & $-0,0178^{*}$ & $-0,0322 *$ & $-0,0467^{*}$ \\
\hline Sexo do chefe da família (homem $=1$ ) & $-0,0181^{*}$ & $-0,00877$ & $-0,0475^{*}$ & $-0,0329 *$ \\
\hline \multicolumn{5}{|l|}{ Características da infra-estrutura escolar } \\
\hline Média de anos de estudo do professor & $-0,00197^{*}$ & $-0,00169$ & $-0,0182 *$ & $-0,0269 *$ \\
\hline Log. da média salarial do professor & $0,0234^{*}$ & 0,00703 & $0,0489 *$ & $-0,0238^{*}$ \\
\hline Proporção de escolas com biblioteca & - & $-0,0247 * * *$ & $-0,00812$ & $-0,614 *$ \\
\hline Proporção de escolas c/ lab. informática & $-0,00685^{* *}$ & - & $-0,0577^{* * *}$ & 0,862 \\
\hline Média de alunos por turma & $-0,000572 * *$ & $-0,00212^{*}$ & $-0,000509$ & $0,00175^{*}$ \\
\hline Repasses do PDDE (média) & - & - & $-0,00374^{*}$ & 0,000763 \\
\hline Repasses do PNAE (média) & 0,000136 & $-0,00943^{* * *}$ & - & $-0,0189^{*}$ \\
\hline Número de observações & 500.255 & 23.322 & 90.873 & 55.572 \\
\hline Teste Razão de Verossimilhança & $120.000^{*}$ & $5.785,30 *$ & $33.995,74^{*}$ & $19.848,76^{*}$ \\
\hline
\end{tabular}

Fonte: resultados da pesquisa

Nota: *denota significância ao nível de $1 \%$; **denota significância ao nível de $5 \%$; ***denota significância ao nível de $10 \%$. 
Ainda com relação a Pernambuco, o atraso escolar da zona urbana pode ser reduzido com aumentos na escolaridade média do professor, na proporção de escolas com laboratório de informática e nos repasses do PDDE. Na área rural, tanto a escolaridade, quanto a renda média do professor podem ser aumentados, para se reduzir a defasagem na escola. Ainda na área rural, também podem ser aumentados a proporção de escolas com bibliotecas e os repasses do PNAE. Ressalta-se, ainda, que a redução do número de alunos por turma parece ser uma estratégia que também alcançaria resultados significativos, na redução do atraso escolar, da zona rural, de Pernambuco.

\section{Conclusões}

Este trabalho propôs-se em realizar uma análise da influência que variáveis associadas a características pessoais e familiares de uma criança, bem como variáveis de infra-estrutura escolar exercem sobre a freqüência e o atraso escolar no ensino fundamental. Para tanto, optouse por comparar as áreas urbana e rural, de Pernambuco e São Paulo.

Os resultados mostraram que meninos estão mais propensos a atrasarem-se nos estudos e menos dispostos a freqüentarem a escola que meninas. Além disso, crianças de cor branca apresentaram uma maior probabilidade de freqüentar a escola e menores chances de ficarem atrasadas nos estudos, se comparadas a pardos ou negros. Conclui-se, com isso, que políticas públicas voltadas para a melhoria dos índices educacionais, no ensino fundamental, devem levar em consideração as diferenças raciais e de gênero existentes nos dois estados.

Notou-se que a escolaridade do chefe de família e a renda familiar per capita exercem influência sobre a freqüência e o atraso escolar. Logo, políticas públicas voltadas para melhorar a escolaridade dos responsáveis pelo lar (como a educação de jovens e adultos) e/ou a renda de famílias pobres, poderão levar a uma melhoria dos índices educacionais de Pernambuco e São Paulo.

Com relação à influência de melhorias na infra-estrutura escolar, os resultados variaram de acordo com a situação do domicílio ou o estado analisado. Por exemplo, uma variação positiva no salário do professor pode melhorar a freqüência escolar da área urbana de Pernambuco e reduzir o atraso escolar, da área rural, do mesmo estado. Já para São 
Paulo, a frequiência à escola pode ser beneficiada com melhorias na escolaridade média do professor, enquanto a defasagem escolar pode ser reduzida mediante investimentos na capacidade física da escola. Em vista disso, as políticas públicas voltadas para melhorar as condições de ensino das escolas deverão levar em conta a realidade econômica do estado ou região, bem como o objetivo final a ser alcançado.

Ressaltam-se, ainda, as diferenças observadas na infra-estrutura das escolas pernambucanas, com relação às escolas paulistas. As tabelas com as médias das variáveis mostram que a proporção de escolas com bibliotecas e laboratórios de informática é bem inferior em Pernambuco. Ainda, segundo os dados do censo demográfico, a média salarial dos professores pernambucanos, que trabalhavam em escolas públicas, é de R \$ 343,03; enquanto em São Paulo essa média correspondia a R \$ 857,34 . Sugere-se, portanto, que as iniciativas voltadas para melhorar a infra-estrutura escolar priorize o Estado de Pernambuco, bem como a região na qual o mesmo está inserido.

Ao longo de toda análise percebeu-se que os indicadores educacionais estudados são mais precários na área rural, se comparados à área urbana. Em estudo sobre a educação brasileira no campo afirma-se que existe uma alta rotatividade de professores no meio rural, provavelmente em função das condições de trabalho e dos salários serem inferiores àqueles obtidos na área urbana. As características físicas das escolas também são bastante precárias, no que compete à disponibilidade de laboratórios de informática, bibliotecas e outros. Além do mais, tanto professores como alunos tem dificuldades de acesso à escola e $69 \%$ das crianças, moradoras da zona rural, que estudam de $5^{\mathrm{a}}$ a $8^{\mathrm{a}}$ série, são estudantes de escolas da zona urbana (Brasil, 2003). As constatações acima descritas e as evidências observadas nesse trabalho levam a concluir que o poder público deve respeitar as dificuldades inerentes ao meio rural, na elaboração de políticas públicas voltadas para a educação.

\section{Referências bibliográficas}

Albernaz, A.; Ferreira, F.G.H.; Franco, C. Qualidade e equidade no ensino fundamental brasileiro. Pesquisa e Planejamento Econômico, v.32, n.3, p.453-476, dez. 2002. 
Arends-Kuenning, M.; Kassouf, A. L.; Fava, A.; Almeida, A. de. The impact of school quality and school incentive programs on children's schooling and work in Brazil. 2004 (mimeog.).

Barros, R.P. de; Mendonça, R. O impacto de três inovações institucionais na educação brasileira. Rio de Janeiro: IPEA, jun. 1998. 61p. (Texto para discussão, 566)

Barros, R.P. de; Mendonça, R.; Santos, D.D.; Quintaes, G. Determinantes do desempenho educacional no Brasil. Rio de Janeiro: IPEA, out. 2001. 33p. (Texto para discussão, 834)

Barros, R.P. de; Ramos L. A note on the temporal evolution of the relationship between wages and education among brazilian primeage males: 1976-1989. Rio de Janeiro: IPEA, 1992. 32p. (Texto para discussão, 279)

Behrman, J.R.; Wolfe, B.L. The socioeconomic impact of schooling in a developing country. The Review of Economics and Statistics, v.66, n.2, p.296-303, May 1984.

Bertagna, R. H. Progressão continuada: limites e possibilidades. Campinas, 2003. 468p. Tese (Doutorado) - Faculdade de Educação, Universidade Estadual de Campinas.

Birdsall, N. Public inputs and child schooling in Brazil. Journal of Development Economics, v.18, n.1, p.67-86, Jun. 1985.

Blom, A.; Holm-Nielsen, L.; Verner, D. Education, earnings, and inequality in Brazil: 1982-1998: implications for education policy. Washington: The World Bank, 2002. http://www.lacea.org./meeting2001/ Vener.pdf (25 Aug. 2003)

Brasil. Leis, decretos etc. Lei no 9.394 de 20 de dezembro de 1996. Diário Oficial, 23 dez. 1996. Seção 1, p.27839. Estabelece as diretrizes e bases da educação nacional. http://www.cidadania-e.com.br/legislacao.asp (03 abr. 2003)

Brasil. Ministério da Educação e Desporto. Estudo sobre o valor mínimo do FUNDEF: relatório final/grupo de trabalho (port. $\mathrm{n}^{\circ} 71$, de 27.01.2003 e $\mathrm{n}^{\circ}$ 212, de 14.02.2003). http://www.mec.gov.br/sef/fundef/default.shtm (10 jul. 2003) 
Brasil. Ministério da Educação e Desporto. Grupo Permanente de Trabalho de Educação do Campo. Referências para uma política nacional de educação do campo: caderno de subsídios. Brasília, out. 2003. 40p. http:// www.inep.gov.br/pesquisa/publicacoes/default.asp (15 set. 2004)

Brasil. Ministério da Educação e Desporto. Instituto Nacional de Estudos e Pesquisas. Sinopses estatísticas da educação básica: Brasil, regiões e Unidades da Federação, 1999-2003. http://www.inep.gov.br/ estatisticas/numeros/2001 (15 abr. 2004)

Card, D.; Krueger, A.B. Does school quality matter ? Returns to education and the characteristics of public schools in the United States. Journal of Political Economy, v.100, n.1, p.1-40, Feb. 1992.

Duflo, E. Schooling and labor market consequences of school construction in Indonesia: evidence from an unusual policy experiment. The American Economic Review, v.91, n.4, p.795-812, 2001.

Ferrão, M.E.; Beltrão, K.I.; Santos, D.P. O impacto de políticas de nãorepetência sobre o aprendizado dos alunos da $4^{\text {a }}$ série. Pesquisa e Planejamento Econômico, v.32, n.3, p.495-513, dez. 2002.

Greene, W.H. Econometric analysis. New York: Macmillan Publishing Company, 2003. 791p.

Holmes, J. Measuring the determinants of school completion in Pakistan: analysis of censoring and selection bias. New Haven: Yale University, Jan. 1999. 42p. (Center discussion paper, 794)

Instituto Brasileiro de Geografia e Estatística. Censo demográfico 2000: microdados: São Paulo (compact disc). Rio de Janeiro, 2000.

Instituto Brasileiro de Geografia e Estatística. Censo demográfico 2000: microdados: Pernambuco (compact disc). Rio de Janeiro, 2000.

Instituto Brasileiro de Geografia e Estatística. Pesquisa nacional por amostra de domicílios 2001: microdados (compact disc). Rio de Janeiro, 2001.

Kassouf, A.L. Returns to education and training program in the brazilian urban and rural sectors. Revista de Economia e Sociologia Rural, v.35, n.2, p.60-76, abr./jun. 1997. 
Kassouf, A.L. Accounting for education, experience and health as investments in human capital. In: Guilhoto, J.J.M.; Hewings, G.J.D. (Org.). Structure and structural change in the brazilian economy: the political economy of Latin America. Burlington: Ashgate Publishing Limited, 2001. p.219-246.

Leon, F.L.L. de; Menezes-Filho. Reprovação, avanço e evasão escolar no Brasil. Pesquisa e Planejamento Econômico, v.32, n.3, p.417-451, dez. 2002.

Pereira, D.J. de S. Diferenças de escolaridade e rendimento do trabalho nas regiões nordeste e sudeste do Brasil. Piracicaba, 2001. 98p. Dissertação (Mestrado) - Escola Superior de Agricultura "Luiz de Queiroz", Universidade de São Paulo.

Tansel, A. Determinants of school attainment of boys and girls in Turkey: individual, household and community factors. Ankara: Middle East Technical University, Feb. 2000. 21p.

Ueda, E.M.; Hoffmann, R. Estimando o retorno da educação no Brasil. Brazilian Journal of Applied Economics, v.6, n.2, p.209-238, abr./ jun. 2002.

Vasconcellos, L.M. Freqüência e atraso escolar e sua relação com a renda familiar no Brasil. São Paulo, 2003. 128p. Tese (Doutorado) - Faculdade de Economia, Administração e Contabilidade, Universidade de São Paulo. 


\section{Anexos}

Tabela 3 - Média e desvio-padrão ${ }^{1}$ das variáveis utilizadas nas regressões para a freqüência escolar - São Paulo e Pernambuco - áreas urbana e rural.

\begin{tabular}{|c|c|c|c|c|}
\hline \multirow{2}{*}{ Variáveis } & \multicolumn{2}{|c|}{ São Paulo } & \multicolumn{2}{|c|}{ Pernambuco } \\
\hline & Urbano & Rural & Urbano & Rural \\
\hline Freqüência escolar & $\begin{array}{c}0,96 \\
(0,18)\end{array}$ & $\begin{array}{c}0,94 \\
(0,23)\end{array}$ & $\begin{array}{c}0,91 \\
(0,28)\end{array}$ & $\begin{array}{c}0,88 \\
(0,32)\end{array}$ \\
\hline Idade & $\begin{array}{l}10,63 \\
(2,28)\end{array}$ & $\begin{array}{c}10,54 \\
(2,28)\end{array}$ & $\begin{array}{l}10,76 \\
(2,27)\end{array}$ & $\begin{array}{c}10,6 \\
(2,28)\end{array}$ \\
\hline Idade ao quadrado & $\begin{array}{l}118,28 \\
(48,4)\end{array}$ & $\begin{array}{c}116,43 \\
(48,32)\end{array}$ & $\begin{array}{l}120,98 \\
(48,31)\end{array}$ & $\begin{array}{c}117,6 \\
(48,32)\end{array}$ \\
\hline Sexo $($ menino $=1)$ & $\begin{array}{c}0,50 \\
(0,49)\end{array}$ & $\begin{array}{c}0,51 \\
(0,49)\end{array}$ & $\begin{array}{c}0,5 \\
(0,49)\end{array}$ & $\begin{array}{c}0,51 \\
(0,49)\end{array}$ \\
\hline Cor ou raça branca & $\begin{array}{c}0,66 \\
(0,47)\end{array}$ & $\begin{array}{c}0,66 \\
(0,47)\end{array}$ & $\begin{array}{c}0,35 \\
(0,48)\end{array}$ & $\begin{array}{c}0,34 \\
(0,47)\end{array}$ \\
\hline Cor ou raça Preta & $\begin{array}{l}0,041 \\
(0,19)\end{array}$ & $\begin{array}{c}0,04 \\
(0,19)\end{array}$ & $\begin{array}{c}0,04 \\
(0,21)\end{array}$ & $\begin{array}{c}0,05 \\
(0,22)\end{array}$ \\
\hline Cor ou raça Amarela & $\begin{array}{l}0,0044 \\
(0,066)\end{array}$ & $\begin{array}{l}0,0046 \\
(0,068)\end{array}$ & $\begin{array}{c}0,0009 \\
(0,03)\end{array}$ & $\begin{array}{l}0,001 \\
(0,04)\end{array}$ \\
\hline Cor ou raça Parda & $\begin{array}{c}0,29 \\
(0,45)\end{array}$ & $\begin{array}{c}0,29 \\
(0,45)\end{array}$ & $\begin{array}{c}0,6 \\
(0,49)\end{array}$ & $\begin{array}{c}0,59 \\
(0,49)\end{array}$ \\
\hline \multicolumn{5}{|l|}{ Mesorregiões } \\
\hline Metropolitana & $\begin{array}{l}0,52 \\
(0,5)\end{array}$ & $\begin{array}{l}0,32 \\
(0,5)\end{array}$ & - & - \\
\hline São José do Rio Preto & $\begin{array}{c}0,03 \\
(0,18)\end{array}$ & $\begin{array}{c}0,06 \\
(0,23)\end{array}$ & - & - \\
\hline Ribeirão Preto & $\begin{array}{c}0,06 \\
(0,24)\end{array}$ & $\begin{array}{c}0,05 \\
(0,21)\end{array}$ & - & - \\
\hline Araçatuba & $\begin{array}{c}0,02 \\
(0,13)\end{array}$ & $\begin{array}{c}0,02 \\
(0,14)\end{array}$ & - & - \\
\hline Bauru & $\begin{array}{c}0,04 \\
(0,19)\end{array}$ & $\begin{array}{c}0,04 \\
(0,19)\end{array}$ & - & - \\
\hline Araraquara & $\begin{array}{c}0,02 \\
(0,14)\end{array}$ & $\begin{array}{c}0,02 \\
(0,14)\end{array}$ & - & - \\
\hline Piracicaba & $\begin{array}{c}0,03 \\
(0,18)\end{array}$ & $\begin{array}{c}0,03 \\
(0,17)\end{array}$ & - & - \\
\hline Campinas & $\begin{array}{c}0,09 \\
(0,28)\end{array}$ & $\begin{array}{c}0,08 \\
(0,27)\end{array}$ & - & - \\
\hline Presidente Prudente & $\begin{array}{c}0,02 \\
(0,14)\end{array}$ & $\begin{array}{c}0,04 \\
(0,21)\end{array}$ & - & - \\
\hline Marília & $\begin{array}{l}0,01 \\
(0,1)\end{array}$ & $\begin{array}{c}0,02 \\
(0,13)\end{array}$ & - & - \\
\hline
\end{tabular}


Tabela 3 - Média e desvio-padrão ${ }^{1}$ das variáveis utilizadas nas regressões para a freqüência escolar - São Paulo e Pernambuco - áreas urbana e rural.

\begin{tabular}{|c|c|c|c|c|}
\hline \multirow{2}{*}{ Variáveis } & \multicolumn{2}{|c|}{ São Paulo } & \multicolumn{2}{|c|}{ Pernambuco } \\
\hline & Urbano & Rural & Urbano & Rural \\
\hline Assis & $\begin{array}{c}0,01 \\
(0,12)\end{array}$ & $\begin{array}{c}0,02 \\
(0,16)\end{array}$ & - & - \\
\hline Itapetininga & $\begin{array}{c}0,02 \\
(0,14)\end{array}$ & $\begin{array}{c}0,07 \\
(0,26)\end{array}$ & - & - \\
\hline Macro-região & $\begin{array}{c}0,06 \\
(0,24)\end{array}$ & $\begin{array}{c}0,12 \\
(0,32)\end{array}$ & - & - \\
\hline Vale do Paraíba & $\begin{array}{c}0,06 \\
(0,23)\end{array}$ & $\begin{array}{c}0,06 \\
(0,24)\end{array}$ & - & - \\
\hline Litoral Sul & $\begin{array}{c}0,01 \\
(0,11)\end{array}$ & $\begin{array}{l}0,04 \\
(0,2)\end{array}$ & - & - \\
\hline Metropolitana & - & - & $\begin{array}{c}0,45 \\
(0,49)\end{array}$ & $\begin{array}{c}0,05 \\
(0,22)\end{array}$ \\
\hline Sertão Pernambucano & - & - & $\begin{array}{c}0,1 \\
(0,3)\end{array}$ & $\begin{array}{c}0,23 \\
(0,42)\end{array}$ \\
\hline São Francisco & - & - & $\begin{array}{c}0,06 \\
(0,23)\end{array}$ & $\begin{array}{c}0,1 \\
(0,3)\end{array}$ \\
\hline Agreste Pernambucano & - & - & $\begin{array}{c}0,23 \\
(0,42)\end{array}$ & $\begin{array}{c}0,41 \\
(0,49)\end{array}$ \\
\hline Zona da Mata & - & - & $\begin{array}{c}0,16 \\
(0,37)\end{array}$ & $\begin{array}{c}0,2 \\
(0,4)\end{array}$ \\
\hline \multicolumn{5}{|l|}{ Características da família } \\
\hline $\begin{array}{l}\text { Log. da renda familiar per } \\
\text { capita }\end{array}$ & $\begin{array}{c}6,73 \\
(0,34)\end{array}$ & $\begin{array}{c}4,32 \\
(1,32)\end{array}$ & $\begin{array}{c}3,6 \\
(1,51)\end{array}$ & $\begin{array}{l}2,89 \\
(1,5)\end{array}$ \\
\hline Idade do chefe da família & $\begin{array}{l}40,32 \\
(9,37)\end{array}$ & $\begin{array}{l}40,51 \\
(9,39)\end{array}$ & $\begin{array}{c}42,18 \\
(11,94)\end{array}$ & $\begin{array}{c}44,35 \\
(11,72)\end{array}$ \\
\hline $\begin{array}{l}\text { Escolaridade do chefe da } \\
\text { família }\end{array}$ & $\begin{array}{c}5,99 \\
(3,69)\end{array}$ & $\begin{array}{c}4,33 \\
(3,08)\end{array}$ & $\begin{array}{c}3,88 \\
(3,55)\end{array}$ & $\begin{array}{c}1,61 \\
(2,13)\end{array}$ \\
\hline $\begin{array}{l}\text { Sexo do chefe da família } \\
\text { (homem }=1 \text { ) }\end{array}$ & $\begin{array}{c}0,78 \\
(0,41)\end{array}$ & $\begin{array}{c}0,88 \\
(0,32)\end{array}$ & $\begin{array}{c}0,70 \\
(0,46)\end{array}$ & $\begin{array}{c}0,87 \\
(0,33)\end{array}$ \\
\hline \multicolumn{5}{|c|}{ Características da infra-estrutura escolar } \\
\hline $\begin{array}{l}\text { Média de anos de estudo } \\
\text { do professor }\end{array}$ & $\begin{array}{l}13,26 \\
(0,49)\end{array}$ & $\begin{array}{l}12,26 \\
(1,79)\end{array}$ & $\begin{array}{l}12,19 \\
(0,61)\end{array}$ & $\begin{array}{l}10,29 \\
(1,29)\end{array}$ \\
\hline $\begin{array}{l}\text { Log. da média salarial do } \\
\text { professor }\end{array}$ & $\begin{array}{c}6,73 \\
(0,34)\end{array}$ & $\begin{array}{c}4,82 \\
(2,83)\end{array}$ & $\begin{array}{c}5,81 \\
(0,24)\end{array}$ & $\begin{array}{c}5,3 \\
(0,53)\end{array}$ \\
\hline $\begin{array}{l}\text { Proporção de escolas com } \\
\text { biblioteca }\end{array}$ & $\begin{array}{c}0,67 \\
(0,15)\end{array}$ & $\begin{array}{c}0,2 \\
(0,28)\end{array}$ & - & $\begin{array}{c}0,02 \\
(0,06)\end{array}$ \\
\hline $\begin{array}{l}\text { Proporção de escolas c/ } \\
\text { lab. informática }\end{array}$ & $\begin{array}{c}0,36 \\
(0,16)\end{array}$ & $\begin{array}{c}0,05 \\
(0,16)\end{array}$ & $\begin{array}{c}0,07 \\
(0,07)\end{array}$ & - \\
\hline
\end{tabular}


Tabela 3 - Média e desvio-padrão ${ }^{1}$ das variáveis utilizadas nas regressões para a freqüência escolar - São Paulo e Pernambuco - áreas urbana e rural.

\begin{tabular}{lcccc}
\hline \multirow{2}{*}{ Variáveis } & \multicolumn{2}{c}{ São Paulo } & \multicolumn{2}{c}{ Pernambuco } \\
\cline { 2 - 5 } & Urbano & Rural & Urbano & Rural \\
\hline \multirow{2}{*}{ Média de alunos por turma } & 34,87 & 28,33 & 34,54 & 42,36 \\
& $(2,53)$ & $(5,81)$ & $(6,48)$ & $(11,3)$ \\
Repasses do PNAE (média) & 2,03 & & 1,53 & 2,14 \\
& $(0,79)$ & - & $(0,74)$ & $(0,58)$ \\
Repasses do PDDE (média) & 21,07 & 22,15 & & - \\
Repasses do FUNDEF & $(24,01)$ & $(24,6)$ & & \\
(média) & - & 20,49 & 14,23 & 20,28 \\
\hline
\end{tabular}

Fonte: Resultados da pesquisa.

Nota: ${ }^{1} \mathrm{O}$ desvio-padrão refere-se aos valores entre parênteses.

Tabela 4 - Média e desvio-padrão ${ }^{1}$ das variáveis utilizadas nas regressões para o atraso escolar - São Paulo e Pernambuco - áreas urbana e rural.

\begin{tabular}{lcccc}
\hline \multirow{2}{*}{ Variáveis } & \multicolumn{2}{c}{ São Paulo } & \multicolumn{2}{c}{ Pernambuco } \\
& Urbano & Rural & Urbano & Rural \\
\hline \multirow{2}{*}{ Atraso escolar } & 0,18 & 0,21 & 0,49 & 0,59 \\
Idade & $(1,15)$ & $(0,41)$ & $(0,49)$ & $(0,49)$ \\
& 11,23 & 11,18 & 12,24 & 12,14 \\
Idade ao quadrado & $(9,32)$ & $(3,15)$ & $(3,67)$ & $(3,79)$ \\
Sexo (menino = 1) & 135,48 & 134,99 & 163,29 & 161,82 \\
& $(226,94)$ & $(77,19)$ & $(97,1)$ & $(100,11)$ \\
Cor ou raça Branca & 0,52 & 0,53 & 0,52 & 0,51 \\
& $(1,51)$ & $(0,49)$ & $(0,49)$ & $(0,49)$ \\
Cor ou raça Preta & 0,65 & 0,66 & 0,36 & 0,35 \\
Cor ou raça Amarela & $(0,47)$ & $(0,47)$ & $(0,47)$ & $(0,48)$ \\
& 0,04 & 0,04 & 0,05 & 0,05 \\
Cor ou raça Parda & $(0,2)$ & $(0,19)$ & $(0,21)$ & $(0,22)$ \\
Mesorregiões & 0,004 & 0,004 & 0,001 & 0,001 \\
Metropolitana & $(0,07)$ & $(0,07)$ & $0,03)$ & $(0,04)$ \\
& 0,29 & 0,29 & 0,59 & 0,59 \\
São José do Rio Preto & $(0,44)$ & $(0,45)$ & $(0,49)$ & $(0,49)$ \\
& & & & \\
& 0,52 & 0,33 & & - \\
& $(0,49)$ & $(0,47)$ & & - \\
& 0,03 & 0,06 & & - \\
\end{tabular}


Tabela 4 - Média e desvio-padrão ${ }^{1}$ das variáveis utilizadas nas regressões para o atraso escolar - São Paulo e Pernambuco - áreas urbana e rural.

\begin{tabular}{|c|c|c|c|c|}
\hline \multirow{2}{*}{ Variáveis } & \multicolumn{2}{|c|}{ São Paulo } & \multicolumn{2}{|c|}{ Pernambuco } \\
\hline & Urbano & Rural & Urbano & Rural \\
\hline Ribeirão Preto & $\begin{array}{c}0,06 \\
(0,21)\end{array}$ & $\begin{array}{c}0,05 \\
(0,22)\end{array}$ & - & - \\
\hline Araçatuba & $\begin{array}{c}0,02 \\
(0,14)\end{array}$ & $\begin{array}{c}0,02 \\
(0,14)\end{array}$ & - & - \\
\hline Bauru & $\begin{array}{c}0,03 \\
(0,21)\end{array}$ & $\begin{array}{c}0,04 \\
(0,22)\end{array}$ & - & - \\
\hline Araraquara & $\begin{array}{c}0,02 \\
(0,13)\end{array}$ & $\begin{array}{c}0,02 \\
(0,14)\end{array}$ & - & - \\
\hline Piracicaba & $\begin{array}{c}0,03 \\
(0,18)\end{array}$ & $\begin{array}{c}0,03 \\
(0,17)\end{array}$ & - & - \\
\hline Campinas & $\begin{array}{c}0,09 \\
(0,29)\end{array}$ & $\begin{array}{c}0,08 \\
(0,27)\end{array}$ & - & - \\
\hline Presidente Prudente & $\begin{array}{c}0,02 \\
(0,16)\end{array}$ & $\begin{array}{c}0,04 \\
(0,21)\end{array}$ & - & - \\
\hline Marília & $\begin{array}{c}0,01 \\
(0,11)\end{array}$ & $\begin{array}{c}0,02 \\
(0,13)\end{array}$ & - & - \\
\hline Assis & $\begin{array}{c}0,01 \\
(0,12)\end{array}$ & $\begin{array}{c}0,02 \\
(0,15)\end{array}$ & - & - \\
\hline Itapetininga & $\begin{array}{c}0,02 \\
(0,15)\end{array}$ & $\begin{array}{c}0,07 \\
(0,26)\end{array}$ & - & - \\
\hline Macro-região & $\begin{array}{c}0,06 \\
(0,24)\end{array}$ & $\begin{array}{c}0,12 \\
(0,32)\end{array}$ & - & - \\
\hline Vale do Paraíba & $\begin{array}{c}0,06 \\
(0,23)\end{array}$ & $\begin{array}{c}0,06 \\
(0,24)\end{array}$ & - & - \\
\hline Litoral Sul & $\begin{array}{c}0,01 \\
(0,12)\end{array}$ & $\begin{array}{c}0,04 \\
(0,19)\end{array}$ & - & - \\
\hline Metropolitana & - & - & $\begin{array}{c}0,46 \\
(0,48)\end{array}$ & $\begin{array}{c}0,05 \\
(0,22)\end{array}$ \\
\hline Sertão Pernambucano & - & - & $\begin{array}{c}0,1 \\
(0,3)\end{array}$ & $\begin{array}{c}0,23 \\
(0,42)\end{array}$ \\
\hline São Francisco & - & - & $\begin{array}{c}0,06 \\
(0,23)\end{array}$ & $\begin{array}{c}0,1 \\
(0,3)\end{array}$ \\
\hline Agreste Pernambucano & - & - & $\begin{array}{c}0,22 \\
(0,41)\end{array}$ & $\begin{array}{c}0,42 \\
(0,49)\end{array}$ \\
\hline Zona da Mata & - & - & $\begin{array}{c}0,16 \\
(0,37)\end{array}$ & $\begin{array}{c}0,2 \\
(0,4)\end{array}$ \\
\hline
\end{tabular}


Tabela 4 - Média e desvio-padrão ${ }^{1}$ das variáveis utilizadas nas regressões para o atraso escolar - São Paulo e Pernambuco - áreas urbana e rural.

\begin{tabular}{|c|c|c|c|c|}
\hline \multirow{2}{*}{ Variáveis } & \multicolumn{2}{|c|}{ São Paulo } & \multicolumn{2}{|c|}{ Pernambuco } \\
\hline & Urbano & Rural & Urbano & Rural \\
\hline \multicolumn{5}{|l|}{ Características da família } \\
\hline $\begin{array}{l}\text { Log. da renda familiar per } \\
\text { capita }\end{array}$ & $\begin{array}{l}4,78 \\
(1,3)\end{array}$ & $\begin{array}{l}4,36 \\
(1,3)\end{array}$ & $\begin{array}{c}3,73 \\
(1,45)\end{array}$ & $\begin{array}{c}2,99 \\
(1,49)\end{array}$ \\
\hline Idade do chefe da família & $\begin{array}{l}40,81 \\
(9,57)\end{array}$ & $\begin{array}{l}41,05 \\
(9,49)\end{array}$ & $\begin{array}{c}43,58 \\
(11,98)\end{array}$ & $\begin{array}{c}45,84 \\
(11,65)\end{array}$ \\
\hline $\begin{array}{l}\text { Escolaridade do chefe da } \\
\text { família }\end{array}$ & $\begin{array}{c}5,88 \\
(3,71)\end{array}$ & $\begin{array}{c}4,28 \\
(3,06)\end{array}$ & $\begin{array}{c}3,89 \\
(3,53)\end{array}$ & $\begin{array}{c}1,63 \\
(2,13)\end{array}$ \\
\hline $\begin{array}{l}\text { Sexo do chefe da família } \\
\text { (homem }=1 \text { ) }\end{array}$ & $\begin{array}{c}0,77 \\
(0,42)\end{array}$ & $\begin{array}{c}0,88 \\
(0,32)\end{array}$ & $\begin{array}{c}0,69 \\
(0,46)\end{array}$ & $\begin{array}{c}0,87 \\
(0,33)\end{array}$ \\
\hline \multicolumn{5}{|c|}{ Características da infra-estrutura escolar } \\
\hline $\begin{array}{l}\text { Média de anos de estudo } \\
\text { do professor }\end{array}$ & $\begin{array}{l}13,26 \\
(1,48)\end{array}$ & $\begin{array}{l}12,27 \\
(1,78)\end{array}$ & $\begin{array}{l}12,19 \\
(0,61)\end{array}$ & $\begin{array}{l}10,29 \\
(1,29)\end{array}$ \\
\hline $\begin{array}{l}\text { Log. da média salarial do } \\
\text { professor }\end{array}$ & $\begin{array}{c}6,73 \\
(1,04)\end{array}$ & $\begin{array}{c}4,82 \\
(2,83)\end{array}$ & $\begin{array}{c}5,81 \\
(0,24)\end{array}$ & $\begin{array}{c}5,29 \\
(0,54)\end{array}$ \\
\hline $\begin{array}{l}\text { Proporção de escolas com } \\
\text { biblioteca }\end{array}$ & - & $\begin{array}{c}0,2 \\
(0,29)\end{array}$ & $\begin{array}{c}0,42 \\
(0,15)\end{array}$ & $\begin{array}{c}0,02 \\
(0,06)\end{array}$ \\
\hline $\begin{array}{l}\text { Proporção de escolas c/ } \\
\text { lab. informática }\end{array}$ & $\begin{array}{c}0,7 \\
(0,15)\end{array}$ & - & $\begin{array}{c}0,07 \\
(0,07)\end{array}$ & $\begin{array}{l}0,0005 \\
(0,003)\end{array}$ \\
\hline Média de alunos por turma & $\begin{array}{l}34,89 \\
(2,55)\end{array}$ & $\begin{array}{l}28,33 \\
(5,83)\end{array}$ & $\begin{array}{l}34,55 \\
(6,69)\end{array}$ & $\begin{array}{c}42,23 \\
(11,32)\end{array}$ \\
\hline Repasses do PDDE (média) & - & - & $\begin{array}{l}12,09 \\
(3,09)\end{array}$ & $\begin{array}{l}14,15 \\
(3,34)\end{array}$ \\
\hline Repasses do PNAE (média) & $\begin{array}{c}2,03 \\
(0,81)\end{array}$ & $\begin{array}{c}2,1 \\
(0,79)\end{array}$ & - & $\begin{array}{c}2,15 \\
(0,57)\end{array}$ \\
\hline
\end{tabular}

Fonte: Resultados da pesquisa.

Nota: ${ }^{1} \mathrm{O}$ desvio-padrão refere-se aos valores entre parênteses.

Recebido em agosto de 2005 e revisto em julho de 2006. 